\title{
MEMBANGUN WEBSITE MANAJEMEN INVESTASI BERBASIS CROWDFUNDING MODUL MONITORING DANA INVESTASI MENGGUNAKAN METODE ITERATIVE INCREMENTAL
}

\author{
${ }^{1}$ Fathimah Muthi Luthfiyah, ${ }^{2}$ Nia Ambarsari, ${ }^{3}$ Taufik Nur Adi \\ 1,2,3Program Studi Sistem Informasi, Fakultas Rekayasa Industri, Universitas Telkom \\ ${ }^{1}$ fathimahmuthiluthfiyah@gmail.com, ${ }^{2}$ ambarsarinia@gmail.com, ${ }^{3}$ taufik.nur.adi@gmail.com
}

\begin{abstract}
Abstrak-Investasi merupakan penanaman dana untuk mengembangkan keuangan dalam sebuah usaha. Di Indonesia, salah satu sektor pembangunan ekonomi nasional yang membutuhkan dana usaha adalah Usaha Kecil dan Menengah (UKM). Permasalahan yang dihadapi UKM adalah sulitnya mencari dana investasi karena adanya keterbatasan informasi dan pengaruh keinginan investor dalam menanamkan dana investasinya. Dana yang telah diinvestasikan harus dipertanggung jawabkan dan dapat diperlihatkan secara transparan kepada investor dalam bentuk laporan keuangan secara berkala untuk dilakukan pengontrolan dan montoring. Pemilihan penyebaran informasi menggunakan website memudahkan UKM dan investor dalam berinteraksi serta berbagi informasi yang dibutuhkan. Banyaknya jumlah UKM dan investor serta kebutuhan terhadap ketersediaan dana, crowdfunding menjadi hal yang bisa diterapkan dalam mencari dana investasi. Crowdfunding adalah dimana sejumlah besar orang secara finansial mendukung sebuah usaha yang akan dijalankan. Website ini juga menerapkan metode iterative incremental yang bisa mengakomodasi jika terjadi perubahan pada tahapan pengembangan yang dilakukan. Analisis dan perancangan website ini menggunakan UML dan bahasa pemrograman PHP framework Codeigniter. Website diuji dengan melakukan blackbox testing kepada user. Hasil pengujian menunjukkan sistem yang dibangun sesuai dengan perancangan sistem dan kebutuhan user. Hasil penelitian ini adalah website yang mempermudah investor dalam melakukan monitoring terhadap dana investasi, juga dapat memudahkan UKM dalam mengolah dana investasi dengan transparan.
\end{abstract}

Kata kunci: manajemen investasi, monitoring, crowdfunding, iterrative incremental

\section{PENDAHULUAN}

Investasi merupakan penanaman dana untuk mengembangkan keuangan agar memperoleh keuntungan di masa depan [1][2]. Investasi menjadi salah satu kebutuhan utama untuk berwirausaha baik dalam memulai atau melanjutkan usaha. Di Indonesia, salah satu sektor pembangunan ekonomi nasional yang membutuhkan dana untuk memulai atau melanjutkan usaha adalah Usaha Kecil dan Menengah (UKM). Kementerian Koperasi dan UKM Republik Indonesia menyatakan bahwa pada Februari 2014 jumlah UKM di Indonesia mencapai 56,5 juta usaha dan diperkirakan akan mencapai angka 58 juta usaha pada akhir tahun 2014. Jumlah usaha yang begitu besar dapat dijadikan peluang untuk menanam dana investasi pada usaha-usaha yang membutuhkan.

Di sisi lain, investasi harus disertai dengan pengelolaan yang baik dengan standar tertentu agar proses peminjaman hingga pengembalian dapat dilakukan dengan baik dan terpercaya. Pengelolaan dana investasi yang disertai dengan ketentuan-ketentuan tertentu dinamakan manajemen investasi. Manajemen investasi memiliki tahapan-tahapan di dalamnya, yaitu penentuan anggaran, penentuan jenis bisnis atau usaha, penilaian risiko investasi, perhitungan keuntungan atas dana investasi, perhitungan waktu pengembalian dana investasi, serta pengontrolan dan monitoring penggunaan dana investasi [3].

Salah satu permasalahan yang sering dihadapi oleh UKM adalah kesulitan dalam mendapatkan dana investasi. Kesulitan UKM dalam mendapatkan dana investasi disebabkan keterbatasan informasi serta persyaratan administratif dan teknis yang harus dipenuhi. Selain itu, kesulitan UKM dalam mendapatkan dana investasi dipengaruhi oleh investor. Para investor masih berpikir dua kali untuk menginvestasikan dananya pada sektor UKM. Ketertarikan berinvestasi bukan didasarkan pada UKM atau jenis bisnis tertentu, tetapi investor sangat memperhatikan risiko-risiko yang akan muncul terhadap aktivitas investasinya.

Terkait dengan penggunaan internet sebagai akses untuk mendapatkan informasi, wilayah Indonesia memilik potensi besar dalam penyebaran informasi karena penggunaan internet penduduk yang cukup tinggi dan meningkat setiap tahunnya. Kementerian Komunikasi dan Informatika (Kemkominfo) menyatakan, pengguna internet di Indonesia hingga saat ini (2013) telah mencapai 82 juta orang. Dengan pencapaian tersebut, Indonesia berada pada peringkat ke-8 di dunia (kominfo.go.id). Bisnis dan usaha pun semakin berkembang dengan adanya kemudahan dalam pencarian dan penyebaran informasi, termasuk dalam bidang investasi. Oleh karena itu, pemilihan penyebaran informasi dengan menggunakan website akan memudahkan UKM dan investor dalam berinteraksi serta berbagi informasi yang mereka butuhkan. 
Di Indonesia, terdapat sebuah website yang khusus menangani pengelolaan dana investasi antara wirausaha dan investor, yaitu bangoen.com. Namun, terdapat beberapa kekurangan pada website tersebut. Tahapan pada manajemen investasi tidak dilakukan secara keseluruhan di dalam website tersebut khususnya perihal monitoring dana investasi, seperti replayment schedule dan mengirimkan laporan keuangan. Akan tetapi, dana yang telah diinvestasikan oleh investor harus dipertanggungjawabkan sesuai dengan tujuan penggunaan dana investasi dan dapat diperlihatkan secara transparan oleh investor dalam bentuk laporan keuangan secara berkala untuk dilakukan pengontrolan dan montoring.

Banyaknya jumlah UKM dan investor serta kebutuhan terhadap ketersediaan dana, crowdfunding menjadi suatu model yang bisa diterapkan bagi bisnis atau usaha yang kesulitan dalam mencari modal usaha. Model crowdfunding akan memudahkan UKM dalam mencari investor dan investor dapat memantau kinerja UKM yang telah mendapatkan dana investasi. Dengan menggunakan model crowdfunding, UKM ataupun investor juga dapat memperluas cakupan pasar dan mendapatkan informasi yang mereka butuhkan.

Berdasarkan penelitian sebelumnya yang dilakukan oleh Sevenirus Dewantara bahwa manfaat yang diperoleh dari perancangan situs crowdfunding ini adalah memudahkan proyek memeroleh modal awal. Bagi masyarakat luas, situs crowdfunding ini dapat menjadi media berdonasi sekaligus mendapatkan reward yang sesuai serta untuk mengenal lebih dalam lagi UKM kreatif di Bandung. Bagi kalangan akademisi, perancangan ini dapat menjadi landasan pengembangan situs crowdfunding di Indonesia yang masih sedikit jumlahnya [4].

\section{METODOLOGI PENELITIAN}

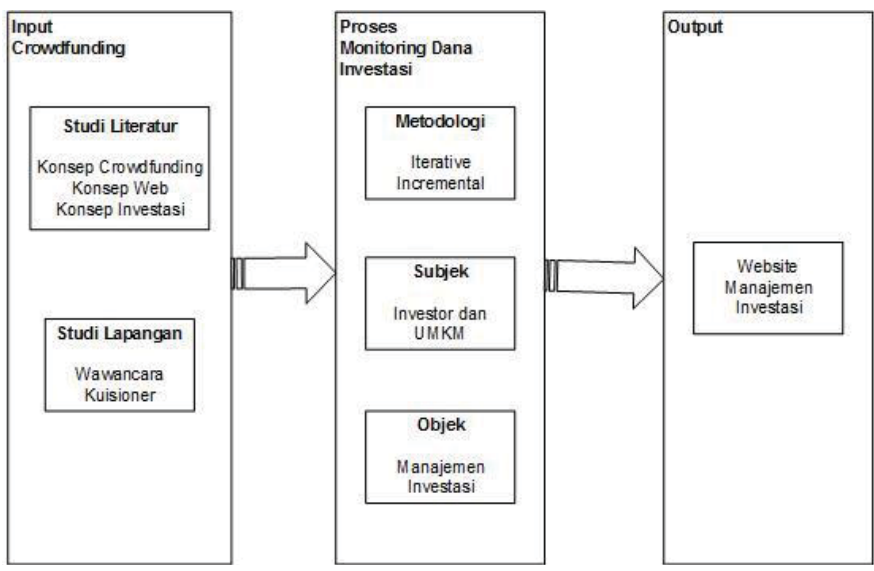

Gambar 1 Model Konseptual

Berdasarkan model konseptual pada Gambar 1 dapat dilihat bahwa model konseptual ini memiliki beberapa elemen utama yaitu input, proses, dan output. Ketiga elemen tersebut merupakan gambaran umum mengenai pembangunan website manajemen investasi dalam hal monitoring dana investasi.

Elemen pertama pada model konseptual yaitu input. Input dari penelitian ini yaitu pemahaman studi literatur terkait konsep crowdfunding, web, dan investasi. Crowdfunding adalah sejumlah besar orang (sebuah kerumunan) secara finansial mendukung sebuah proyek atau usaha (Mike Wicks, 2013: 5). Pada elemen ini juga dilakukan studi lapangan melalui wawancara dan kuisioner kepada UKM dan investor.

Elemen kedua yaitu proses. Proses yang dilakukan menggunakan metode iterative incremental, yaitu Setiap aplikasi yang dihasilkan dari suatu iterasi dapat dilakukan evaluasi, hasil dari evaluasi tersebut menjadi feedback untuk iterasi berikutnya. Ada empat tahap dalam metode iterative incremental, yaitu tahap inception berfokus pada analisis latar belakang, perumusan masalah, serta mendefinisikan lingkup kerja, tahap elaboration berfokus pada analisis dan disain, tahap construction, akan dilakukan pengembangan piranti lunak (software), dan yang terakhir adalah tahap transition, akan dilakukan pengujian dan pengenalan produk yang telah dihasilkan kepada pengguna [5].

Dalam tahap-tahap tersebut terdapat lagi subtahap, yaitu business modeling, requirement, analysis and design, implementation, dan testing. Pada tahap business modeling, dilakukan analisis mengenai latar belakang, ruang lingkup, tujuan, dan adanya masukan dari user. Pada tahap requirement, business model dianalisis dan menghasilkan usecase diagram, activity diagram, mockup, dan feedback. Pada tahap analysis and design menghasilkan sequence diagram, class diagram, package diagram, design database, dan deployment diagram. Tahap implementation merupakan tahap coding terhadap aplikasi. Tahap yang terakhir adalah tahap testing, pada tahap ini dilakukan pengujian berupa blackbox testing kepada user.

Elemen ketiga yaitu output. Output yang dihasilkan berupa website manajemen investasi yang memiliki fungsi untuk melakukan monitoring dana investasi.

\section{HASIL DAN PEMBAHASAN}

\section{A. Tahap Inception}

Merupakan tahap awal untuk menganalisis kebutuhan sistem yang akan dibangun.

Pada website yang akan dibangun teridentifikasi tiga kebutuhan inti yang harus ada, sesuai dengan Tabel I. Kebutuhan pertama adalah manajemen konfigurasi user sebagai UKM yang dilakukan oleh administrator, kebutuhan kedua adalah manajemen konfigurasi user sebagai investor, dan kebutuhan ketiga adalah manajemen monitoring terhadap dana yang telah diinvestasikan dengan tujuan agar investor dapat melakukan monitoring terhadap dana yang telah diinvestasikan.

Pada Tabel II dijelaskan bahwa aktor dalam sistem dibagi menjadi tiga bagian, yaitu UKM, investor, dan viewer. UKM merupakan user yang melakukan registrasi ke aplikasi ini, mampu mengisi laporan penggunaan dan pengembalian dana, melakukan rescheduling (perubahan jangka waktu pengembalian dana). Investor merupakan user yang melakukan registrasi ke aplikasi ini dan memonitoring perkembangan penggunaan dan pengembalian dana investasi yang telah diberikan kepada UKM. Viewer hanya dapat melihat informasi yang disajikan di dalam website. 
TABEL I

IDENTIFIKASI KEBUTUHAN SISTEM

\begin{tabular}{|c|c|c|c|}
\hline No & $\begin{array}{c}\text { Nama } \\
\text { Kebutuhan }\end{array}$ & Deskripsi & $\begin{array}{c}\text { Sumber } \\
\text { (User) }\end{array}$ \\
\hline 1. & $\begin{array}{l}\text { Mengisi } \\
\text { laporan } \\
\text { penggunaan } \\
\text { dana }\end{array}$ & $\begin{array}{l}\text { Proses untuk mengisi laporan } \\
\text { penggunaan dana yang telah } \\
\text { diinvestasikan }\end{array}$ & UKM \\
\hline 2. & $\begin{array}{l}\text { Melihat } \\
\text { laporan } \\
\text { penggunaan } \\
\text { dana }\end{array}$ & $\begin{array}{l}\text { Proses untuk melihat } \\
\text { penggunaan dana investasi } \\
\text { yang digunakan oleh UKM } \\
\text { sehingga investor dapat melihat } \\
\text { perkembangan penggunaan } \\
\text { dana tersebut }\end{array}$ & $\begin{array}{l}\text { UKM, } \\
\text { Investor }\end{array}$ \\
\hline 3. & $\begin{array}{l}\text { Mengisi } \\
\text { laporan } \\
\text { pengembalian } \\
\text { dana }\end{array}$ & $\begin{array}{l}\text { Proses untuk mengisi laporang } \\
\text { pengembalian dana yang telah } \\
\text { diinvestasikan sesuai dengan } \\
\text { waktu kesepakatan yang telah } \\
\text { disepakati bersama antara } \\
\text { UKM dan Investor }\end{array}$ & UKM \\
\hline 4. & $\begin{array}{l}\text { Melihat } \\
\text { laporan } \\
\text { pengembalian } \\
\text { dana }\end{array}$ & $\begin{array}{l}\text { Proses untuk melihat laporan } \\
\text { pengembalian dana apakah } \\
\text { sesuai dengan kesepakatan } \\
\text { jangka waktu pengembalian }\end{array}$ & $\begin{array}{l}\text { UKM, } \\
\text { Investor, } \\
\text { Viewer }\end{array}$ \\
\hline 5. & $\begin{array}{l}\text { Melakukan } \\
\text { rescheduling }\end{array}$ & $\begin{array}{l}\text { Proses untuk menyusun } \\
\text { kembali jadwal pengembalian } \\
\text { dana yang akan disepakati } \\
\text { bersama antara UKM dan } \\
\text { Invesotr }\end{array}$ & $\begin{array}{l}\text { UKM, } \\
\text { Investor }\end{array}$ \\
\hline 6. & $\begin{array}{l}\text { Melihat } \\
\text { rating UKM }\end{array}$ & $\begin{array}{l}\text { Proses untuk melihat rating } \\
\text { UKM }\end{array}$ & $\begin{array}{l}\text { UKM, } \\
\text { Investor, } \\
\text { Viewer }\end{array}$ \\
\hline
\end{tabular}

TABEL II

AKTOR SISTEM

\begin{tabular}{|l|l|l|}
\hline No & Nama Aktor & \multicolumn{1}{c|}{ Deskripsi } \\
\hline 1. & UKM & $\begin{array}{l}\text { Aktor yang dapat melakukan pengajuan } \\
\text { pinjaman dana kepada investo dan } \\
\text { memberikan laporan penggunaan serta } \\
\text { pengembalian dana }\end{array}$ \\
\hline 2. & Investor & $\begin{array}{l}\text { Aktor yang dapat melihat laporan } \\
\text { penggunaan dan pengembalian dana } \\
\text { investasi serta menerima atau menolak } \\
\text { permintaan reschedule dari UKM }\end{array}$ \\
\hline 3. & Viewer & $\begin{array}{l}\text { Aktor yang hanya dapat melihat informasi } \\
\text { mengenai raitng UKM dan informasi jenis } \\
\text { usaha UKM }\end{array}$ \\
\hline
\end{tabular}

Usecase memiliki tiga aktor utama seperti yang telah dijelaskan dalam aktor sistem. UKM mampu mengisi serta melihat laporan penggunaan dan pengembalian dana, UKM juga dapat melakukan rescheduling (perubahan jadwal jangka waktu pengembalian dana). Investor mampu melihat laporan penggunaan dan pengembalian dana yang dilakukan oleh UKM, investor juga dapat menerima permohonan rescheduling. Sementara viewer hanya mampu melihat informasi mengenai rating UKM dan jenis usaha UKM.

Setiap usecase akan dijelaskan dalam satu usecase scenario seperti yang tertulis pada Tabel III, IV, dan V. Usecase scenario menjelaskan usecase diagram secara spesifik dengan menggambarkan alur-alur proses yang terjadi di dalamnya.
TABEL III

USECASE SCENARIO-MENGISI LAPORAN PENGGUNAAN DANA

\begin{tabular}{|c|c|c|}
\hline Nama & \multicolumn{2}{|c|}{ Mengisi laporan penggunaan dana } \\
\hline Prioritas & \multicolumn{2}{|l|}{ Tinggi } \\
\hline Aktor & \multicolumn{2}{|l|}{ UKM } \\
\hline $\begin{array}{l}\text { Pre } \\
\text { condition }\end{array}$ & \multicolumn{2}{|c|}{$\begin{array}{lr}- & \text { Tela } \\
- & \text { Tela } \\
\text { pelaporan } & \\
\end{array}$} \\
\hline $\begin{array}{l}\text { Post } \\
\text { condition }\end{array}$ & \multicolumn{2}{|c|}{$\begin{array}{l}\text { Investor dan UKM dapat melihat laporan penggunaan } \\
\text { dana }\end{array}$} \\
\hline Description & \multicolumn{2}{|c|}{$\begin{array}{l}\text { UKM mengisi laporan penggunaan dana dan omset yang } \\
\text { di dapatkan dengan waktu secara berkala yang telah } \\
\text { disepakati bersama oleh investor }\end{array}$} \\
\hline \multirow{2}{*}{\multicolumn{2}{|c|}{ UKM }} & Sistem \\
\hline & & $\begin{array}{l}\text { 1. Menampilkan form } \\
\text { laporan penggunaan dana }\end{array}$ \\
\hline \multicolumn{3}{|c|}{$\begin{array}{lc}2 . & \text { Mengisi form } \\
\text { laporang penggunaan dana }\end{array}$} \\
\hline \multirow{2}{*}{\multicolumn{2}{|c|}{$\begin{array}{l} \\
4 . \quad \text { Melihat laporan } \\
\text { penggunaan dana }\end{array}$}} & $\begin{array}{l}3 . \quad \text { Update laporan } \\
\text { penggunaan dana }\end{array}$ \\
\hline & & \\
\hline
\end{tabular}

TABEL IV

USECASE SCENARIO-RESCHEDULING

\begin{tabular}{|c|c|c|c|}
\hline Nama & \multicolumn{3}{|c|}{ Rescheduling } \\
\hline Prioritas & \multicolumn{3}{|c|}{ Tinggi } \\
\hline Aktor & \multicolumn{3}{|c|}{ UKM, Investor } \\
\hline Pre condition & \multicolumn{3}{|c|}{$\begin{array}{l}\text { UKM tidak melakukan pelaporan pengembalian dana } \\
\text { secara rutin }\end{array}$} \\
\hline $\begin{array}{l}\text { Post } \\
\text { condition }\end{array}$ & \multicolumn{3}{|c|}{$\begin{array}{l}\text { Investor memiliki jadwal baru untuk pengembalian } \\
\text { dana }\end{array}$} \\
\hline Description & \multicolumn{3}{|c|}{$\begin{array}{l}\text { UKM melakukan perubahan jadwal pengembalian dana } \\
\text { yang telah disetujui bersama oleh investor }\end{array}$} \\
\hline \multicolumn{2}{|l|}{ UKM } & $\begin{array}{c}\text { Iah disetujui bersama oleh } \\
\text { Sistem }\end{array}$ & Investor \\
\hline & & $\begin{array}{ll}\text { 2. } & \text { Menampilkan form } \\
\text { reschedule repayment } \\
\text { schedule }\end{array}$ & \\
\hline \multicolumn{2}{|c|}{ 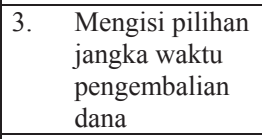 } & & \\
\hline & & & 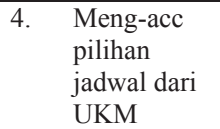 \\
\hline & & $\begin{array}{l}\text { 5. Update repayment } \\
\text { schedule }\end{array}$ & \\
\hline & & $\begin{array}{ll}6 . & \text { Menampilkan } \\
& \text { reschedule } \\
& \text { repayment schedule }\end{array}$ & \\
\hline \multicolumn{2}{|c|}{$\begin{array}{ll}\text { 7. } & \begin{array}{l}\text { Mengisi laporan } \\
\text { pengembalian } \\
\text { dana }\end{array} \\
\end{array}$} & & \\
\hline Alur alternatif & \multicolumn{3}{|c|}{$\begin{array}{l}\text { Reconsitioning (menghilangkan bunga, emmbayar } \\
\text { pokok pinjaman saja) }\end{array}$} \\
\hline
\end{tabular}


TABEL V

USECASE SCENARIO-MENGISI LAPORAN PENGEMBALIAN DANA

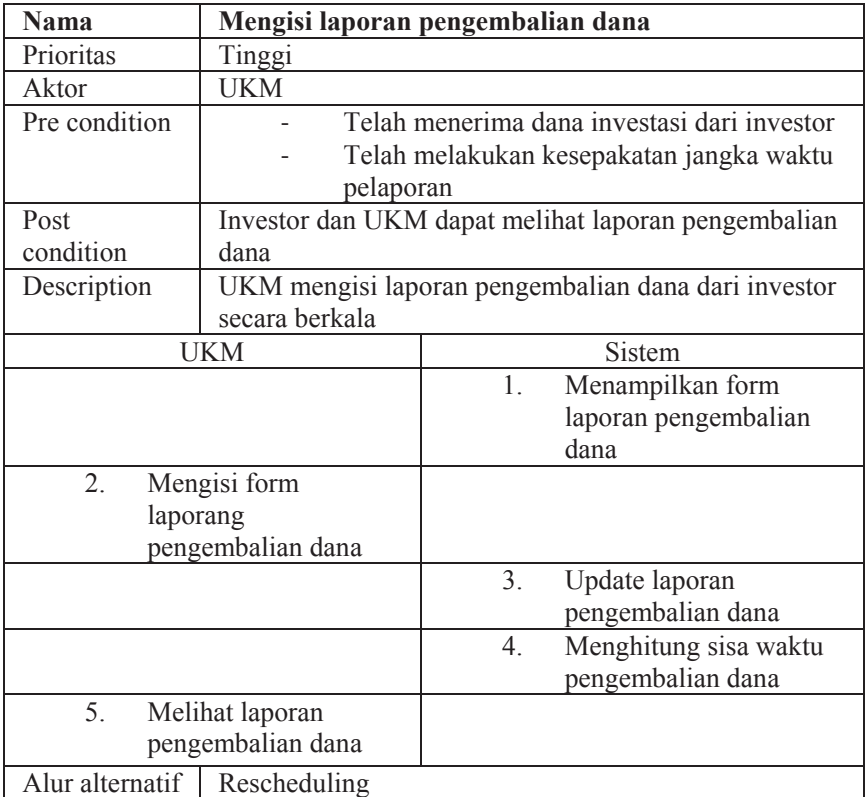

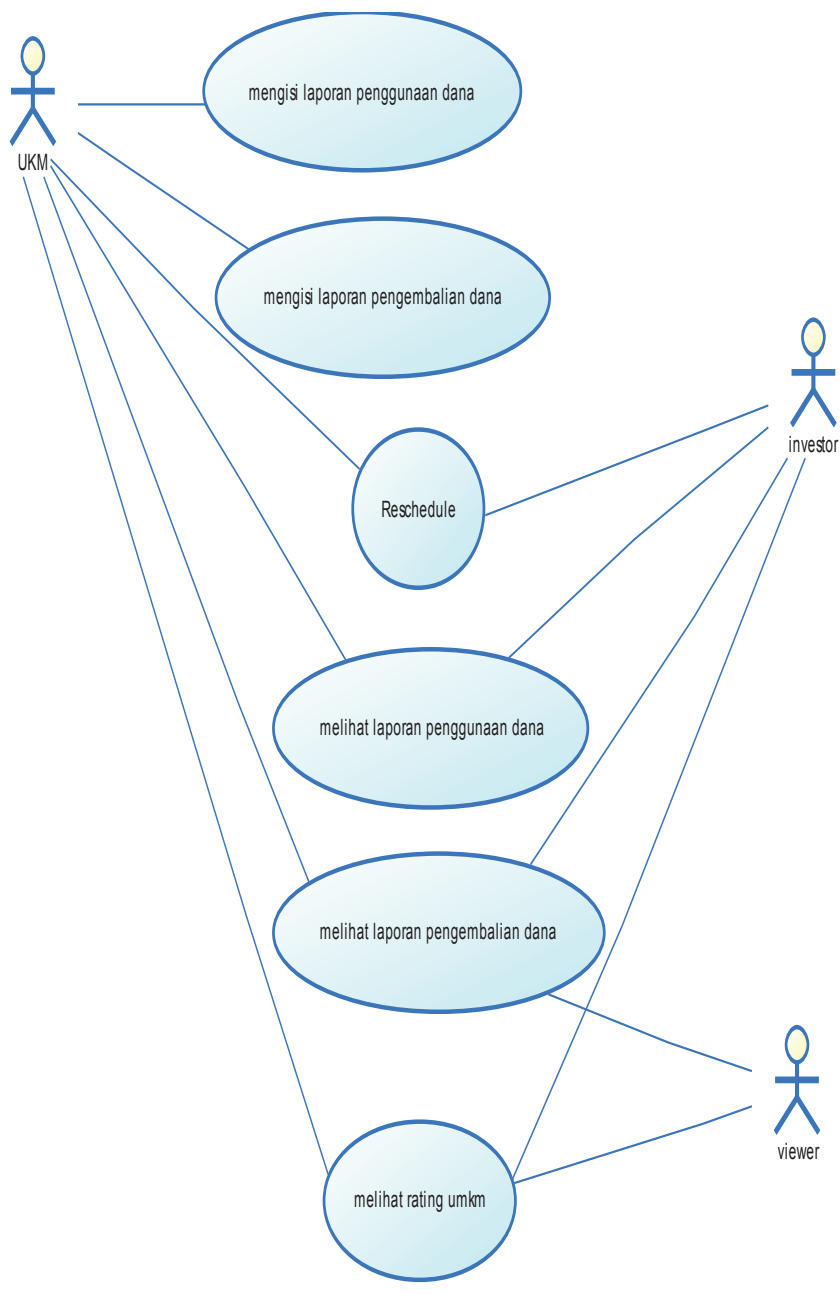

Gambar 2 Usecase Monitoring Dana Investasi

\section{B. Tahap Elaboration}

Pada tahap elaboration dirancang activity diagram pada Gambar 3, 4, dan 5 yang digunakan untuk menggambarkan keterkaitan objek dengan alur kerja dan mendeskripsikan pemrosesan secara paralel. Gambar 3, menjelaskan alur dalam mengisi laporan penggunaan dana yang melibatkan sistem dan UKM sebagai user. Sistem menampilkan form pengisian laporan penggunaan dana, kemudian UKM mengisi form tersebut, jika telah selesai mengisi maka sistem akan melakukan update data laporan dan UKM dapat melihat daftar rincian semua laporan yang pernah dimasukkan.

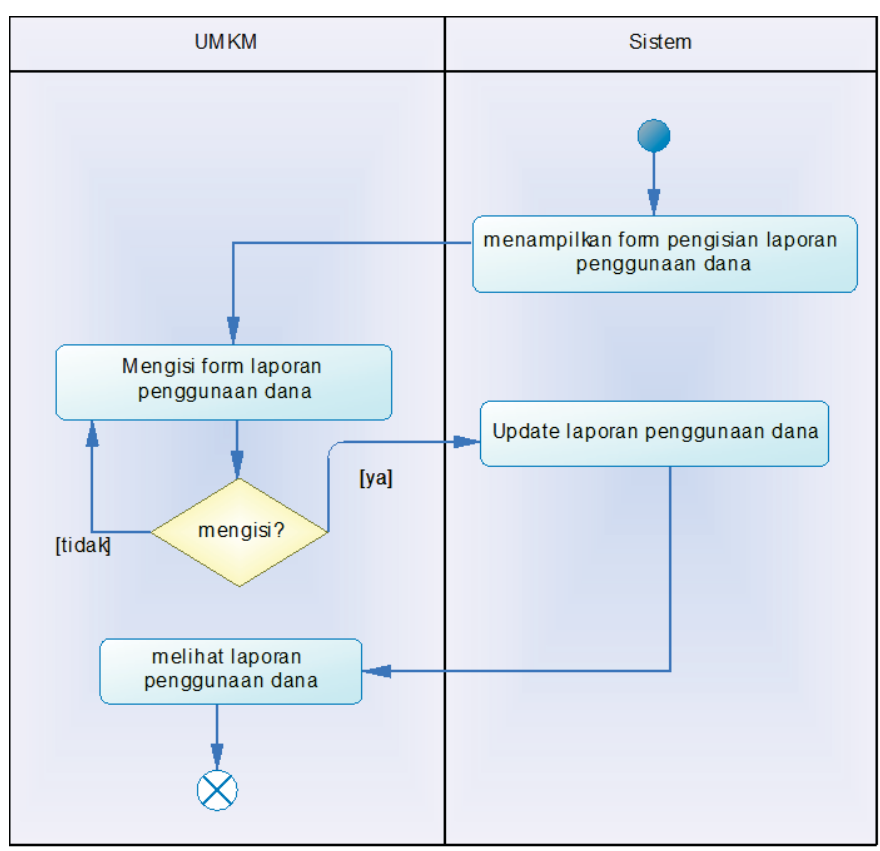

Gambar 3 Mengisi Laporan Penggunaan Dana

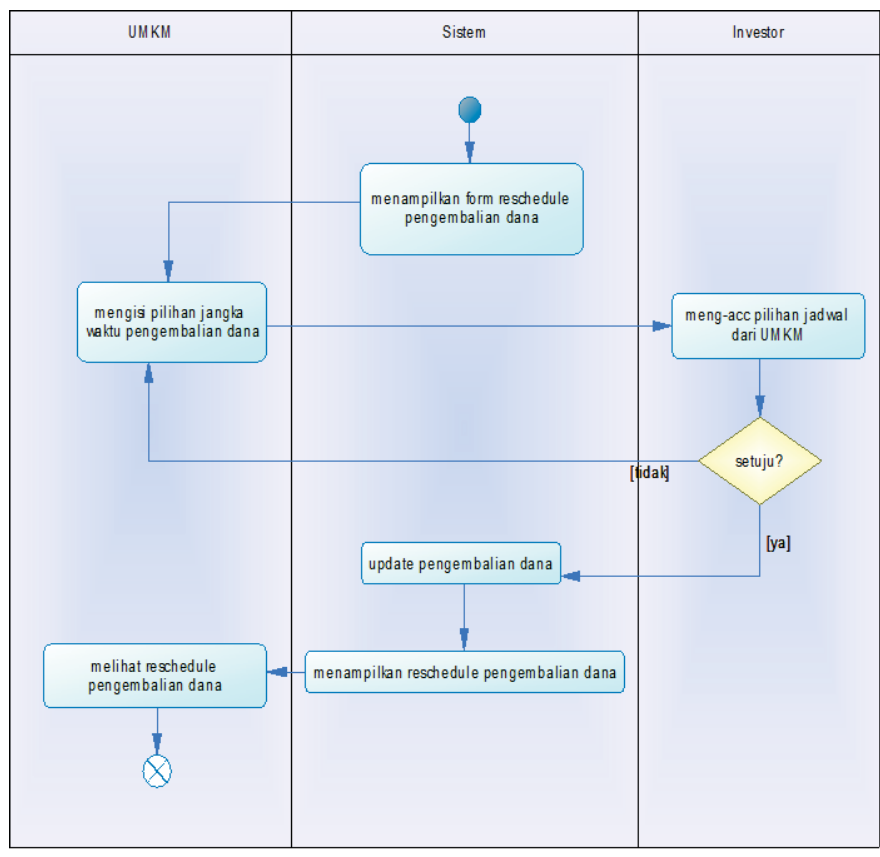

Gambar 4 Rescheduling 
Pada Gambar 4, menjelaskan alur dalam meminta persetujuan reschedule terhadap periode pengembalian dana yang melibatkan sistem, UKM, dan investor. Sistem menampilkan form reschedule, kemudian UKM memilih periode waktu pengembalian dana, investor lalu menerima atau menolak persetujuan reschedule. Jika investor menerima maka sistem akan melakukan update periode pengembalian dana, sedangkan jika investor menolak maka sistem akan memberitahukan UKM untuk melakukan reschedule kembali.

Pada Gambar 5, menjelaskan alur mengisi laporan pengembalian dana yang melibatkan sistem dengan UKM. Sistem menampilkan form pegisian laporan pengembalian dana. Kemudian UKM mengisi form tersebut. Jika telah terisi, sistem akan melakukan update. Jika tidak mengisi sesuai jadwal, maka sistem akan memberitahukan UKM untuk melakukan reschedule.

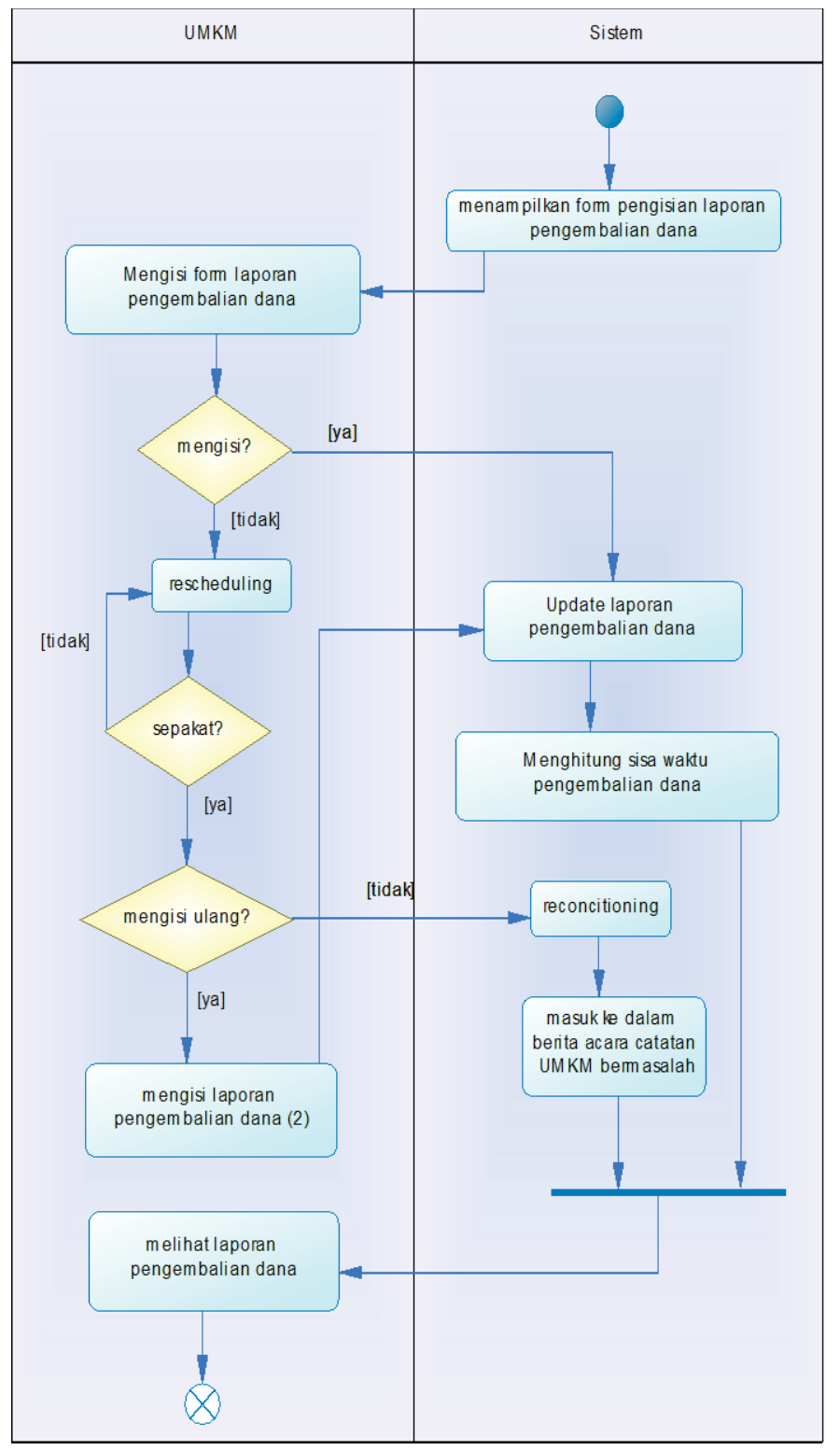

Gambar 5 Mengisi laporan pengembalian dana
Pada tahap ini juga dipetakan class diagram. Class diagram pada Gambar 9 memperlihatkan hubungan antar-class pada pembangunan website manajemen investasi.

\section{Tahap Construction}

Tahap ini memfokuskan pada pengembangan piranti lunak untuk menghasilkan prototype atau produk piranti lunak. Tahap ini lebih menekankan pada fase implementasi seperti yang digambarkan pada Gambar 6.

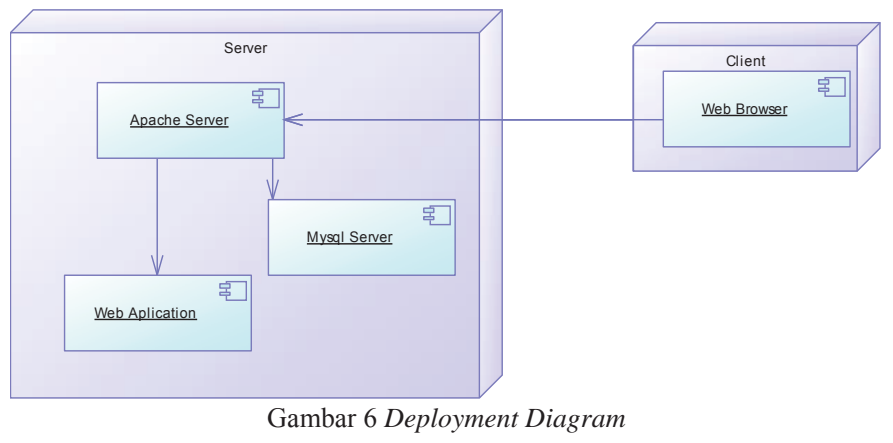

Website ini dibangun menggunakan framework codeigniter dan bahasa pemrograman PHP. Dengan mengimplementasikan model view dan controller. Gambar 7 memperlihatkan tampilan website ketika UKM akan mengisi laporan penggunaan dana.

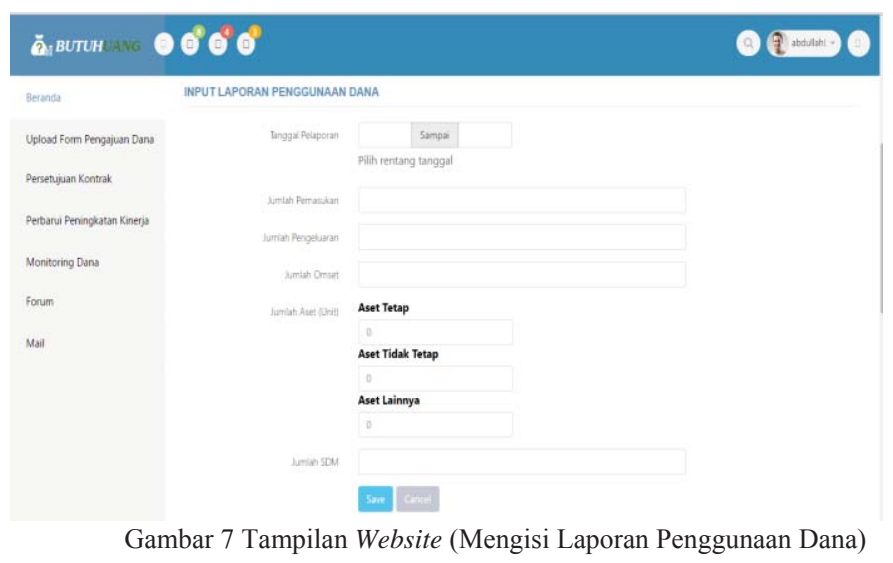

Gambar 8 memperlihatkan tampilan berupa daftar laporan penggunaan dana. UKM dan investor dapat melihat daftar laporan melalui tabel seperti yang tercantum dalam gambar.
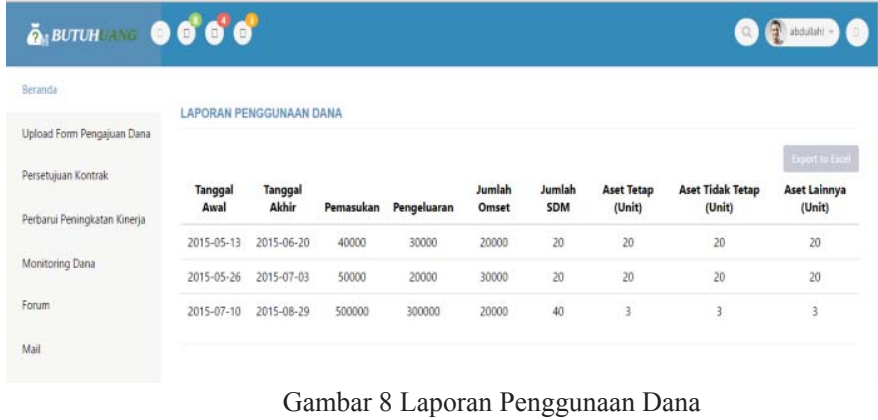


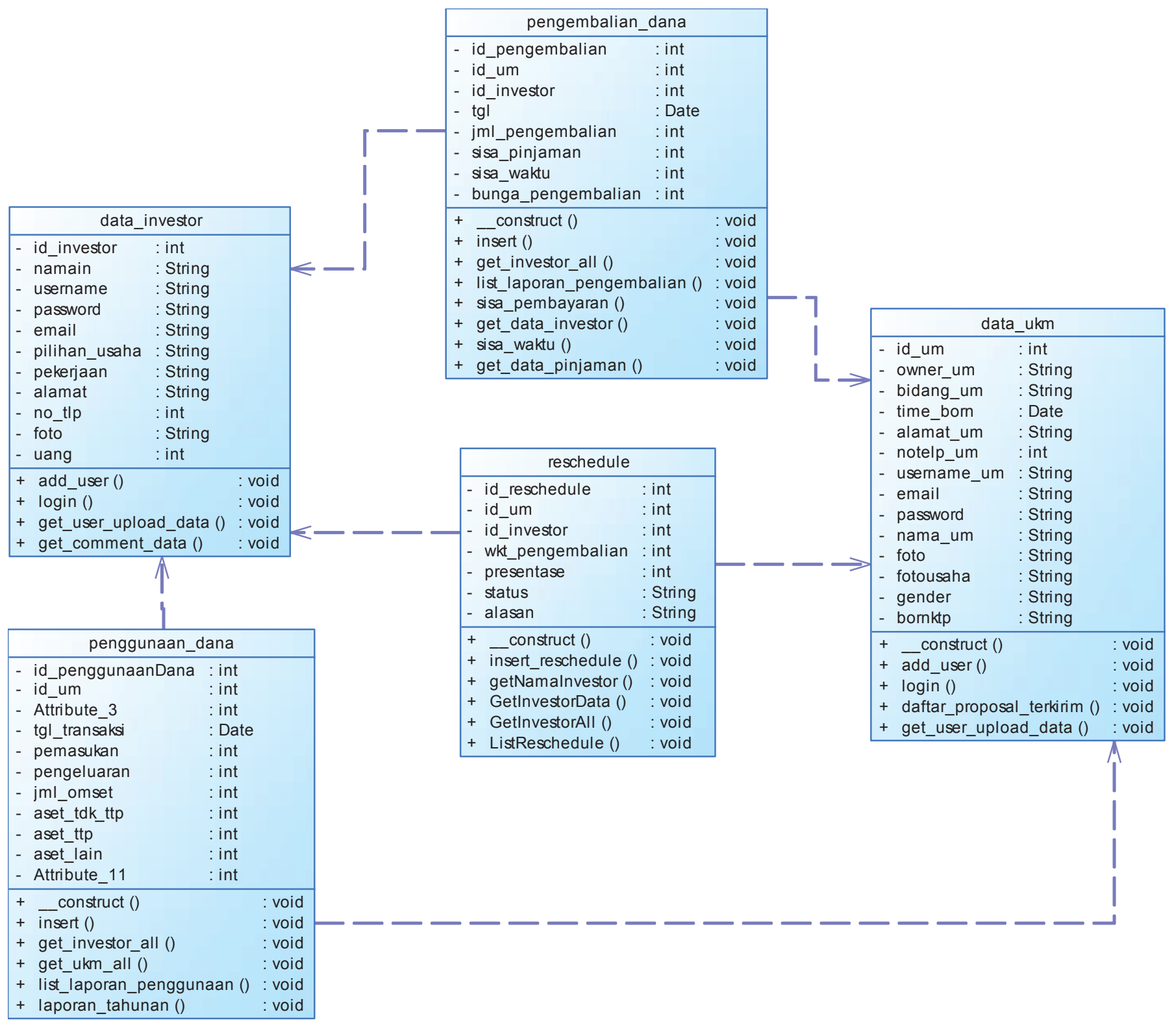

Gambar 9 Class Diagram 
D. Tahap Transition

Tahap transition berfokus pada memperkenalkan produk yang dihasilkan kepada user, menyelesaikan pengujian terhadap aplikasi yang telah dibangun. Pada Tabel VI digambarkan skenario pengujian yang dilakukan kepada user. Beberapa aktivitas yang dilakukan dalam pengujian terhadap website manajemen investasi. Aktivitas berupa input laporan penggunaan dana, input laporan pengembalian dana serta mengajukan reschedule dilakukan oleh UKM, sedangkan aktivitas berupa review laporan penggunaan dana, review laporan pengembalian dana, dan menerima atau menolak persetujuan reschedule dilakukan oleh investor.

TABEL VI

RENCANA PENGUJIAN

\begin{tabular}{|c|l|l|l|c|}
\hline No & \multicolumn{1}{|c|}{ Aktivitas } & \multicolumn{1}{|c|}{ Pengujian } & $\begin{array}{c}\text { Jenis } \\
\text { Pengujian }\end{array}$ & Kode \\
\hline 1 & $\begin{array}{l}\text { Input laporan } \\
\text { penggunaan dana }\end{array}$ & Skenario benar & Blackbox & U3-01 \\
\hline 2 & $\begin{array}{l}\text { Input laporan } \\
\text { pengembalian dana }\end{array}$ & Skenario benar & Blackbox & U3-02 \\
\hline 3 & $\begin{array}{l}\text { Mengajukan } \\
\text { reschedule }\end{array}$ & Skenario benar & Blackbox & U3-03 \\
\hline 4 & $\begin{array}{l}\text { Review Laporan } \\
\text { penggunaan dana }\end{array}$ & Skenario benar & Blackbox & U3-04 \\
\hline 5 & $\begin{array}{l}\text { Review laporan } \\
\text { pengembalian dana }\end{array}$ & Skenario benar & Blackbox & U3-05 \\
\hline 6 & $\begin{array}{l}\text { Menerima / menolak } \\
\text { persetujuan } \\
\text { reschedule }\end{array}$ & $\begin{array}{l}\text { 1. Skenario terima } \\
\text { 2. Skenario tolak }\end{array}$ & $\begin{array}{l}\text { Blackbox } \\
\text { Blackbox }\end{array}$ & $\begin{array}{l}\text { U3-06 } \\
\text { U3-07 }\end{array}$ \\
\hline
\end{tabular}

\section{KESIIMPULAN}

Pembangunan website manajemen investasi pada penelitian ini menggunakan metode iterative incremental yang memiliki empat tahap di dalamnya, yaitu inception, elaboration, construction, dan elaboration. Website yang dibangun berfungsi sebagai monitoring dana terhadap dana yang diinvestasikan oleh investor kepada UKM dengan berisi laporan penggunaan dan pengembalian dana serta permintaan persetujuan reschedule pengembalian dana. Dalam laporan peenggunaan dan pengembalian dana, website manajemen investasi menampilkan default tanggal yang sesuai agar UKM dapat memberikan laporan sesuai dengan periode waktu yang telah disepakati. UKM dapat melakukan reschedule ketika sistem memberikan notifikasi bahwa UKM tersebut harus melakukan reschedule ketika melewati tanggal pengembalian dana yang sudah ditetapkan di dalam sistem. Jika UKM telah melakukan reschedule namun tidak mengembalikan dan memberikan laporan pengembalian dana, maka UKS tersebut akan masuk ke dalam daftar UKM yang tidak direkomendasikan oleh sistem. Hal ini membuat investor lebih mudah dalam menyeleksi UKM yang akan diberikan dana investasi.

\section{DAFTAR PUSTAKA}

[1] Kamus Besar Bahasa Indonesia (KBBI).

[2] www.pakarinvestasi.com diakses pada 24 Juni 2015

[3] Puspopranoto, Sawaldjo. 2006. Manajemen Bisnis, PP, Jakarta.

[4] Dewantara, Severinus. 2013. Perancangan Situs Crowdfunding untuk UKM Kreatif di Bandung. Tugas Akhir, Program Sarjana Disain Komunikasi Visual, Sekolah Komunikasi Multimedia Institut Manajemen Telkom.

[5] Rahmawan, Bobby. 2013. Membangun Portal Web Crowdsourcing Health Treatment dengan Menggunakan Metode Iterative Incremental. Tugas Akhir, Program Sarjana Sistem Informasi, Universitas Telkom 